\title{
Out of Multiple-Choice-Test-Oriented Education--to Production-Oriented Approach
}

\author{
Yanping Lu \\ Shandong Institute of Business and Technology, Yantai, Shandong, China \\ 735337068@qq.com
}

Keywords: MCT, MCT-oriented education, washback, POA

\begin{abstract}
The paper starts with an alarm that MCQ turned out dumb test-takers and ruined a generation of Chinese English learners! Stuck to a MCT-oriented fallacy, the trend is going on and spreading to hamper the whole educational system! MCT is just one of the tools of measurement of English proficiency but not the one and only measure, nor the guideline or the end of language education. As a way out, the author adopts POA in NHCE teaching and concludes with amazing results.
\end{abstract}

\section{Introduction}

A multiple-choice test (MCT hereafter), sometime called "selected-response test, " usually has dozens of questions or "items". For each question, the test- taker is supposed to select the "best" choice among a set of four or more options. Multiple-choice items are an inexpensive and efficient way to check on factual ("declarative") knowledge and routine procedures. Most standardized tests, including state exams and most commercial achievement tests, are made up primarily of multiple-choice items, eg. TOEFL, GRE, IELTS, CET4\&6.

There are reasons for its popularity. First, it is considered fair, of a high degree of objectivity and reliability. Second, it is easy both for teachers to write, implement, and grade and for students to prepare for, predict and perform. Third, considering the scale of tests, it is efficient and economical, especially when the answer sheets can be read and graded by OCR machines.

However, they are not useful for assessing critical or higher thinking in a subject, the ability to write or speak a language, or the ability to apply knowledge to solve problems. The worst come when education becomes MCT-oriented.

\section{The Negative Washback of MCT in English Teaching and Learning}

First, it is an indirect testing and can't test the real language ability of the candidates. Many Chinese students have studied English for many years, are good at doing MCTs, and earning good grades, but can not speak out and are bad at listening and reading comprehension, especially incompetent at writing, thus become victims of dumb English. As a matter of fact, MCT is not a valid testing tool, because in real life, people rarely communicate by multiple-choice questions and selected responses, but by speaking, listening, reading and writing.

Second, although multiple-choice test (MCT) is an inexpensive and efficient way to check on factual ("declarative") knowledge and routine procedures, they are not useful for assessing critical thinking in a subject, the ability to write, or the ability to apply knowledge or solve problems. Because it is easy both for teachers to write, implement, and grade and for students to prepare, predict and perform, MCTs are naturally favored by teachers and students. When this becomes the major form of assessment, the students consider that to learn English well is to do well in answering multiple-choice questions. And the teachers focus on teaching how to do multiple-choice questions. They spend much time on teaching the skills for doing MCTs, such as guessing, excluding etc. The students can do the multiple choice questions even without understanding the topic or text. It turns out good test-takers who can only check or blacken the right answers but can neither speak nor 
write well, not even spell well.

Third, it is unfair and dangerous to use the MCT results as the only measure for candidates' performance or achievements. Just as a well-scored written test can not guarantee a qualified driver, how could (s)he be granted the driver's license? But some students get their diplomas, their certificates for CET4 and CET6 when they pass the MCT while knowing little how to speak or write. Even some teachers are misled to believe that getting high scores in the examination shows the test-takers' high level of English.

Last but the worst, when MCT is not used as means or one of the assessment tools but as the end, the objective of teaching and learning, it may misguide curriculum design and instruction, and influence policy-making in education. Moreover, the impact of testing upon teaching and learning even ripples to educational system and the society as a whole ( Zou Shen, 2005.) The larger a test scale is, the greater impact it will produce. A major danger with high stakes multiple-choice and short-answer tests -- tests that have a major impact on curriculum and instruction -- is that only things that are easily measured are taught. What is easily measurable may not be as important as what is not measurable or is more difficult to measure. When narrow tests define important learning, instruction often gets reduced to "drill and kill" - - lots of practice on questions that look just like the test. In this case, students often get no chance to read books, to ask questions, to listen and speak, to have discussions or debates, to challenge texts, to conduct experiments, to write essays, to explore new ideas - in short, to really learn and acquire the English language.

\section{It Is Time to Change, to POA}

It is well known to all that in real life, one seldom faces multiple-choice questions; one faces and deals with life itself. The real purpose of learning English is to acquire the ability to listen to, to speak, to read, and to write in this language, and to communicate with people who speak the language, not just the ability to do MCTs.

To get away from the negative washback of MCT calls for some drastic change both in theory and practice. The 1980's hailed in two influential theories in the field of language acquisition - the input hypothesis and the output hypothesis. Krashen $(1982 ; 1985)$ claimed that language acquisition depends on fulfilling two key requisites:(a) sufficient comprehensible input in the target language and (b) a low affective filter on the part of the students. But he overplayed the role of input, deeming it as the decisive factor in language acquisition, and ignored the role of output. While recognizing the importance of input, Swain (1985,1995) supplemented the four essential functions of output-- 1) Enhance the fluency of the target language; 2) Verify language hypothesis; 3 ) Raise awareness of the language gap; 4) Develop meta-language skills.

When the input hypothesis was introduced to China in 1980's, China was at a time of scarcity. Except for some poorly compiled textbooks, materials in foreign languages were hardly to be found. Sufficient input was out of the question. But upon 1990's and the 21st century, when sufficient input is out of question, language acquisition is still far from proficient. Then Swain's output hypothesis began to attract the attention of the foreign language teaching community. Since 2000, the domestic

journals have been publishing studies of the theory of the output hypothesis, foreign research results, and investigations into the relationship between the output hypothesis and foreign language teaching in China.

The most notable in China is the "Production Oriented Approach (POA)" proposed by Qiufang Wen $(2008,2015)$. This is a new approach to foreign language teaching with Chinese characteristics, which has aroused wide attention and resonance among experts, scholars and teachers at home and abroad. The prototype of this method is "output driven hypothesis", aiming at reform of education of English majors. In 2013, it was expanded to college English teaching and was officially named POA in October 2014. In terms of the number of journal articles recorded in the CNKI by November 25, 2016 there are only a handful of papers on this subject, most of which are about the theory, with only one dressing the application of this theory in college English teaching, though. 
There remains much room for exploration in practice.

\section{POA in College English Classroom Teaching}

Language consists not only of knowledge, but more of application. Knowledge depends on input, but the application ability depends on communication. It is a two-way process of input and output. Production-oriented classroom instruction focuses on language use rather than language knowledge.

The teaching process we designed is shown in the figure below. First, teachers design genuine and reasonable output tasks as goals and students make the first attempts to fulfill the tasks. Second, teachers input materials and suggestions for the output target and students read the textbook, research for useful information, investigate, and work out the problems. Third, teachers provide necessary help and students prepare for the final output. Fourth, teachers give feedbacks while students make representations in class or online. And each step is interrelated to one another, working as an interactive process.

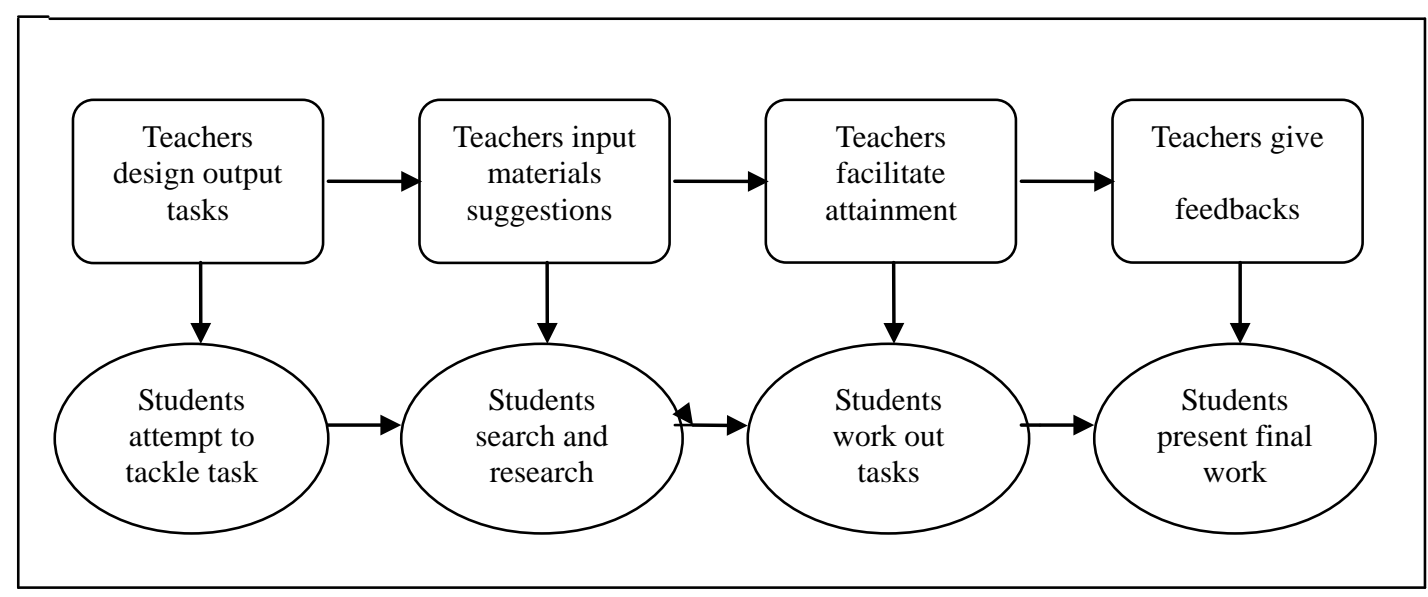

The textbook we use is "New Horizon College English (NHCE)," which fully embodies the change information technology brings to education and creates a digital platform to integrate classroom teaching with autonomous learning. With Unipus APP, Microlectures, self-directed learning guidebooks, students can learn the new words, read the text, and do the exercises and assignments, investigation and research, all by themselves or in groups. Self-directed learning can be personalized, for everyone goes at his or her own pace out of class, hence enhance the efficiency in class. What we do in class is ask questions, have discussions or debates, role play, presentations, and problem-solving, all most all output or production-oriented activities.

What is good about the textbook (NHCE third edition) is that text reading comprehension has changed from multiple choice questions back to short-answer questions and open-ended questions that call for critical thinking, which are consciously used to initiate discussions or debates and writings. And "Unit Project" is a new design in each unit to arrange comprehensive language tasks based on unit subject, in a variety of forms such as speech, retelling, summarizing, discussion or debate, oral reports and PPT representation in class, which train and demonstrate not only students' ability of using the language, but also their ability of critical thinking, research, communication, cooperation, and creative problem-solving.

Take Unit One for example. After the lead-in and the reading of the text A, which took 2 periods, at the end of which task-based homework was assigned. For the next week, students did dubbing, role play, and some creative students adapted the text story into a play: "Love Is a Fallacy!" But it was not all play; we tackled text B, at the end of which Unit Project was allotted to study groups. The last 2 periods saw many successful presentations both in form of team work and individual talk show.

Unit 2 is about beauty. After the text reading, we had a debate on the topic "Is makeover the right 
thing to do?” And to represent beauty, students were encouraged to write poems, with unexpected amazing works turned out!

\section{Conclusion}

It is only 6 weeks since we switched to POA, but it is quite a makeover for me and my students. We conclude:

(1) POA integrates language learning with language use, offline with online, in class with after class, and input with output.

(2) Students' initiative and the effect of classroom learning are obviously optimized.

(3) Critical thinking ability, problem-solving ability and the spirit of cooperation improve.

(4) Getting away from MCTs and anxiety factors, students learn to use English in communicative and creative ways, instead of for tests only.

(5) With POA at work, in the stead of "teacher dominating" it is "teacher facilitating student learning," and, we become happy teachers and merry learners.

\section{Acknowledgement}

This paper is part of the research project "Research on the Optimization of College English Classroom Teaching Based on Production-Oriented Method" sponsored by: the Educational Reform Project of Shandong Provincial Education Department in 2016 (Project No. C2016M056).

\section{References}

[1] S. D. Krashen, Principles and Practice in Second Language Acquisition. Oxford: Pergamon Press, 1982.

[2] S. D. Krashen The Input Hypothesis: Issues and Implications. London: Longman, 1985.

[3] M. Swain. Communicative Competence: Some Roles of Comprehensible Input and Comprehensible Output in the Development[A]. S. Gass and C. Madden (eds). Input in Second Language Acquisition[C]. Rowley, MA: Newbury House,1985.

[4] M. Swain. Three functions of output in second language learning [A]. In G. Cook \& B. Seidlhofer (eds.). Principles and Practice in Applied Linguistics: Studies in Honor of H.G. Widdowson [C]. Oxford: Oxford University Press. 1995:125-144.

[5] Qiufang Wen. The Production-oriented Approach to Teaching University Students English in China [J]. Language Teaching, 2016. Doi:10.1017/S026144481600001X.

[6] Qiufang Wen. Reform of Output -driven Hypothesis and English Major Curriculum Reform[J]. Foreign Language, [J]2008,(2):2-9.

[7] Qiufang Wen. POA: An Attempt to Build a College Foreign Language Classroom Teaching Theory [J]. Chinese Foreign Language Education, 2014,(2):1-12.

[8] Qiufang Wen. Construction of POA Theory System [J]. Foreign Language Teaching and Research, 2015,(4):547-558.

[9] Pin Qi, Xiaochun Shi. An Empirical Study on the Cultivation of College Students' Listening and Speaking practice [J]. Foreign Language, 2015, (6):132-135.

[10]Zuo Shen.1998. English Language Testing—Some Theoretical and Practical Considerations. Shanghai: Shanghai Foreign Language Education Press. 